DOI: $10.5277 /$ epe 160109

\title{
REDUCTION OF ENVIRONMENTAL IMPACT BY INCORPORATING PERFORMANCE ORIENTED LIFE CYCLE ASSESSMENT
}

\begin{abstract}
The result of the study have been presented on life cycle assessment used to assess new manufacturing methods for sustainability and design from environmental perspective. The sustainable product development integrated with life cycle assessment has been used for design of ensuring sustainable product. The objective of the present investigation was to develop a systematic method with environmental consciousness in the selection of alternative materials used in the components, meeting the performance and functional requirements and reducing the environmental impact associated with the product life cycle. The experiments were carried out using a monoblock pump stator and rotor subassembly components. The environmental impact of $\mathrm{CO}_{2}, \mathrm{SO}_{2}$, dichlorobenzene, ethene, and chlorofluorocarbon (CFC-11) has been evaluated by the Centrum Voor Milieukunde Leiden (CML) methods during the process of metallurgy and refining, manufacturing, life cycle assessment (operation) and disposal and recycle. It was observed that there will be considerable reduction in pollutant emission and environmental impact.
\end{abstract}

\section{INTRODUCTION}

Industries are inevitable sources for a country's progress in many aspects. Industries have been contributing factors for enhancing economic growth as well as environment pollution. The needs and demands of human beings are satisfied by products and services produced from an industry [1]. In the recent years, emission of various gases has increased remarkably because of tremendous energy use resulting in global warming. Therefore, to reduce the environmental degradation, eco-materials are considered a major source $[2,3]$. To evaluate such vulnerable environments, many modern trends like life cycle assessment (LCA), life cycle costing (LCC) and life cycle optimization (LCO)

${ }^{1}$ Department of Mechanical Engineering, Hindusthan College of Engineering and Technology, Othakkalmandapam, Coimbatore-641032, India, e-mail: prathu135@gmail.com

${ }^{2}$ Adithya Institute of Technology, Kurumba Palayam, Coimbatore-641107, India. 
have emerged. LCA is a modern method of product evaluation from cradle to crave [4]. The assessment includes various fields such as material agglomeration, processing, manufacturing, transport, maintenance with or without recyclability of the end products $[5,6]$.

In the study made by Vinodh and Rathod [7] of the sustainable product development model was integrated with environmentally conscious quality function deployment (ECQFD) and LCA was used for ensuring sustainable product design. This method was reported to be practically feasible and compatible. Premrudee et al. [8] stated that global warming and acidification are the largest environmental impacts associated with conventional batteries and suggested that changing from conventional to calcium-maintenance free batteries able to minimize the environmental impact. Senthilkumaran et al. [9] presented the relationships between the total cost of products and the various eco-costs concerned with the life cycle of the product and suggested that LCECA mathematical model provided feasible alternative for cost effective and eco-friendly products. Kharel and Charmondusit [10] concluded that the innovative process modification will improve the eco-efficiency in the iron rod industry. Eliceche et al. [11] proposed that environmental life cycle impact played a major role in selecting optimal operating conditions to minimize the consumption of natural gas, electricity and operating cost. Vinodh et al. [12] found that dehumidification process affects the environment due to the production of CFCs and $\mathrm{NO}_{x}$. Eco-indicator and CML technologies where used to assess the environmental impact of an instrument panel. Inspired with the environmental impact and LCA approach, the present research work deals with the development of a systematic method which includes consideration of environmental factors in the selection and processing of components, satisfying functional and performance requirements while minimizing environmental impact on the product.

\section{METHODS}

The method of the study followed in this research is shown in Fig. 1. The study started with the selection of the product (monoblock pump), raw material and manufacturing process, extraction of subassemblies: stator (steel) and rotor (steel and aluminium) and implementing CML methods to estimate the emission. This was followed by study and selection of alternative material of cold rolled grain oriented steel (CRGO) for stator sub-assembly and CRGO steel and aluminium alloy (LM6) chosen for rotor. LCA software $\mathrm{GaBi}$ was used to estimate the emission and the result was compared with the existing subassembly components. The load and no load tests were carried out on the proposed material subassemblies to ensure the efficiency of the pump is maintained. 


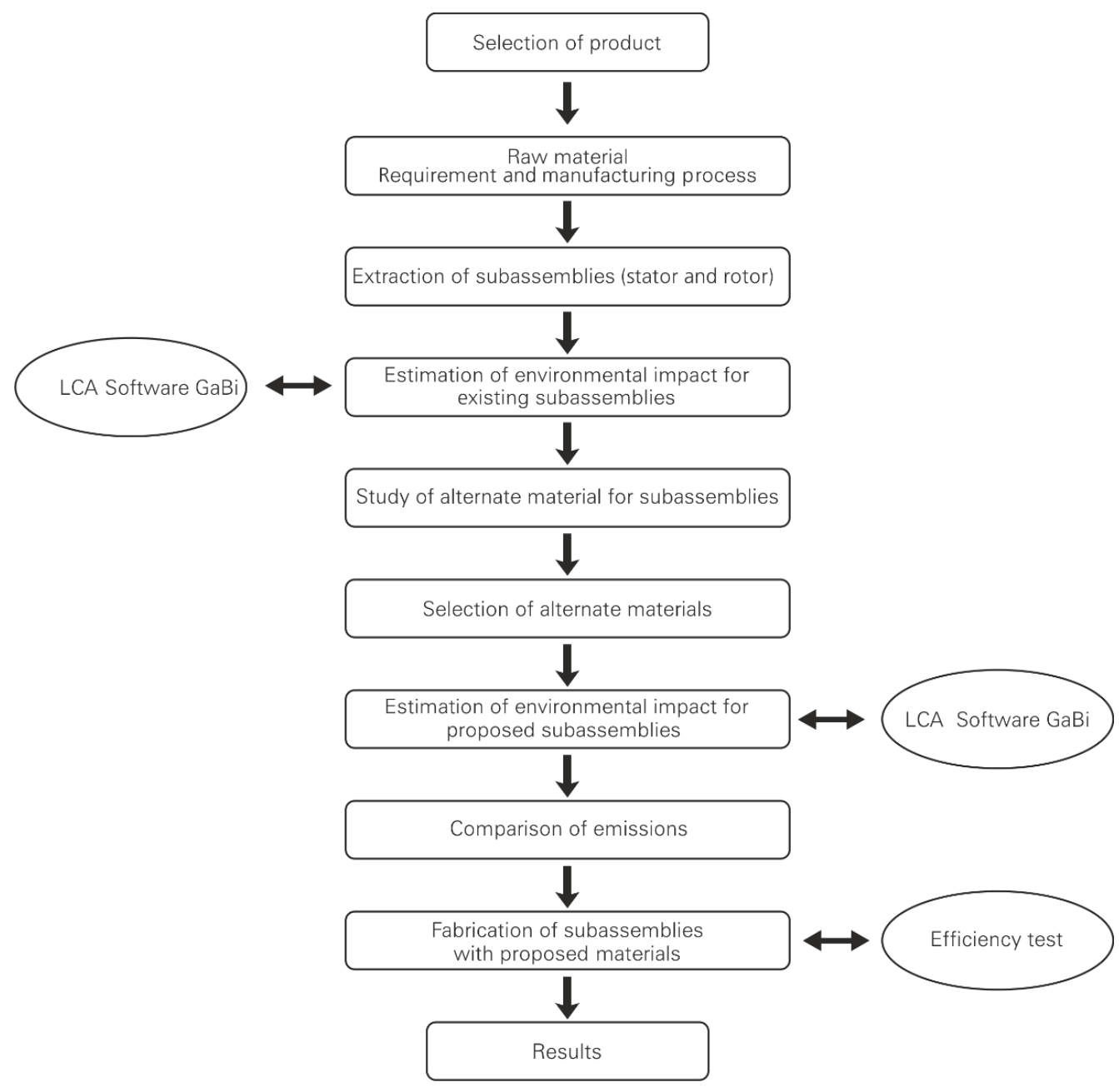

Fig. 1. Method of the study

\subsection{LIFE CYCLE ASSESSMENT (LCA) APPROACH}

The method of LCA approach was carried out according to the sequence of ISO 14040 and 14044 standards recommendations $[13,14]$. The optimal choice of alternative material and the manufacturing process were also in relation to environmental needs with the following aspects:

- environmental impact associated with selection of alternative material,

- environmental impact associated with manufacturing process,

- environmental impact associated with end-of-life (recycle or disposal). 
The four significant phases in LCA approaches are: (i) goal and scope of inquisition, (ii) inventory analysis, (iii) impact assessment and (iv) interpretation. The phases are interdependent for successful completion of the process and reduced environmental impact in the interpretation phase.

\subsection{GOAL AND SCOPE OF INQUISITION}

The main objective of this work was to suggest low environment impact alternative material for monoblock pump subassemblies like stator and rotor. The goal and scope includes technical details like functional unit, system boundaries, and the impact categories that guide subsequent work. The functional unit considered for a $0.5 \mathrm{HP}$ mono-block pump usage is typically over the period of 4 years for the following specification: a total head of $39 \mathrm{~m}, 2.43 \mathrm{~m}^{3} / \mathrm{h}$ discharges with the input power of $282 \mathrm{~W}$. The boundaries of the selected subassembly studied extend to include raw materials, production, transportation (of raw materials, products and waste), utilization and disposal. The analytical boundaries of subassembly are shown in Fig. 2. Various environmental factors such as global warming, acidification, photochemical oxidant creation, human toxicity and ozone depletion are evaluated by the CML method using commercially used LCA software GaBi.

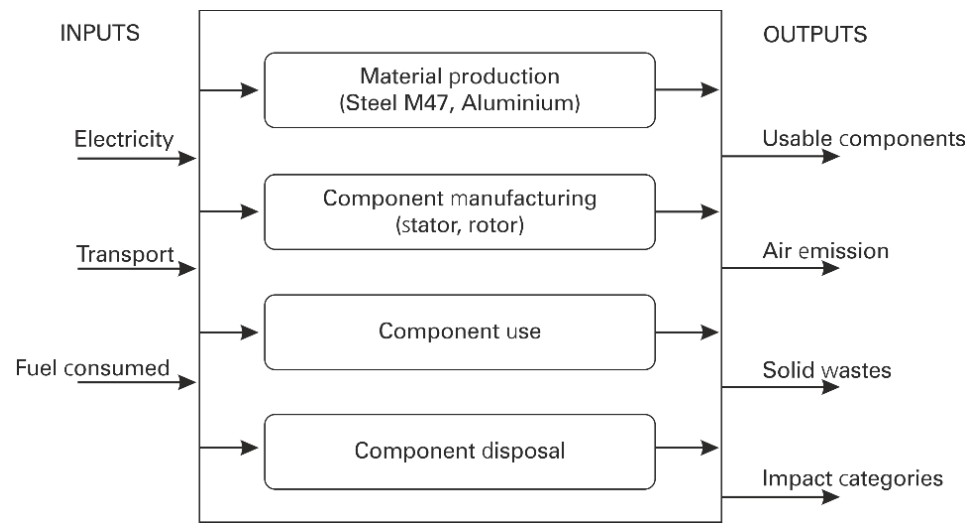

Fig. 2. System boundary diagram

\subsection{INVENTORY ANALYSIS IN LCA}

The data was collected from a monoblock pump component manufacturing organization located in Coimbatore, Tamil Nadu, India. Stator and rotor data was collected in each and every processing unit. Data is inclusive of energy, raw material and physical characteristics. The existing and proposed stator and rotor material composition, material processing from ore mining to disposal and reuse which comprise intermediate stages like transportation distance, metallurgy and refining, manufacture process and operations are shown in Figs. 3 and 4. 

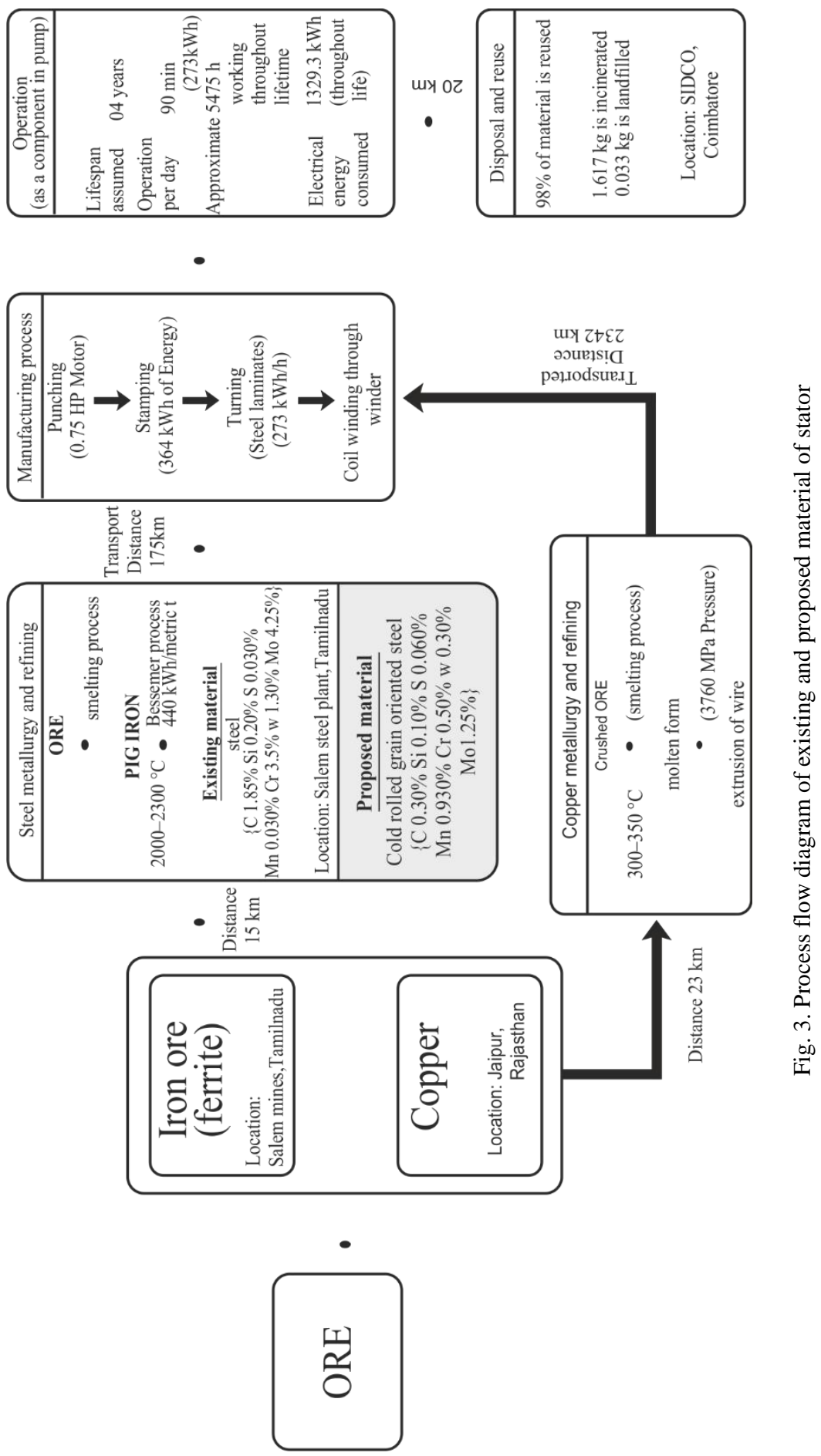

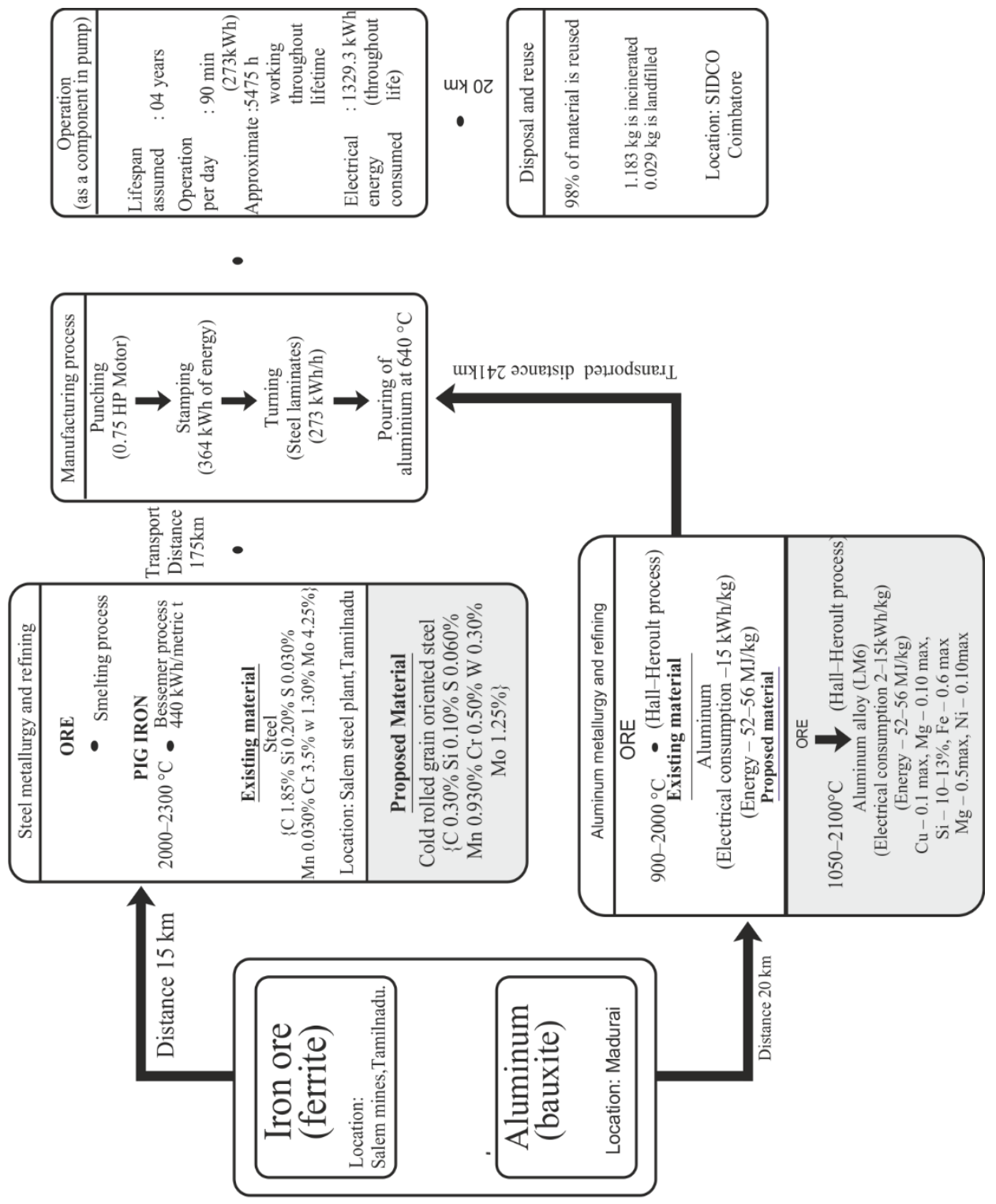

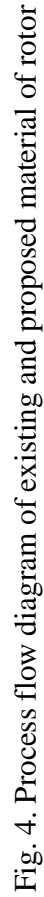

$\frac{1}{0}$ 


\section{RESULTS}

\subsection{METHOD}

CML focuses on a series of environmental impact categories expressed in terms of emissions to the environment or resource use. It allows one to establish an artificial economic value for each unit of environmental impact and to compare the results for different environmental impact categories with each other. The environment impact result is derived from the CML method by using the GaBi software [14]. The CML method has been applied to various case studies such as instrumental panel of electric car [12], self-vibratory drilling machine over traditional drilling machine [15], houses with alternate exterior walls [16], eucalyptus TCF pulp manufacturing [17], etc., which results in finding the environmental hotspots or impacts based on the manufacturing process and materials.

\subsection{ENVIRONMENTAL IMPACT EVALUATION}

The main attribute of this investigation was to evaluate overall environmental impact considering the contribution of the environmental categories such as global warming, acidification, photochemical oxidant creation, human toxicity and ozone depletion. These categories are described in the following sections. From this investigation, the product developers will be able to evaluate the environmental impact of their product and can be more conscious on how to reduce it.

Global warming is caused by emission of greenhouse gases of methane which is depicted as equivalents to $\mathrm{CO}_{2}$, which is produced by burning of fossil fuels. Earth weather is directly propositional to global warming because greenhouse gases absorb the radiated energy from the earth converting it to heat. Manufacturing of stator and rotor with existing material (steel and aluminium) emits $72 \mathrm{~kg}$ and $25.42 \mathrm{~kg}$ of $\mathrm{CO}_{2}$, respectively. Figure 5a shows the proposed alternate material of (CRGO) for stator subassembly and CRGO steel and aluminium alloy (LM6) for rotor. It can be seen that $\mathrm{CO}_{2}$ emission is $44 \%$ and $28 \%$, which is lesser than the existing one.

Acidification is based on the contribution of $\mathrm{SO}_{2}, \mathrm{NO}_{2}$ and other acidic emission produced during manufacturing process. The high-level impact is attributed to the release of large amounts of $\mathrm{SO}_{2}$ during ore processing and manufacture processing of stator and rotor. The computational investigation shows that the emission of $\mathrm{SO}_{2}$ in stator and rotor is $0.15 \mathrm{~kg}$ and $0.05 \mathrm{~kg}$ in existing material, respectively. From Figure $5 \mathrm{~b}$ it is clear that the proposed material (CRGO steel and aluminium alloy) generates $0.101 \mathrm{~kg}$ and $0.039 \mathrm{~kg}$ of $\mathrm{SO}_{2}$, which is $31 \%$ and $17 \%$ lesser than the emissions with existing material (steel and aluminium).

Human toxicity is caused by the emission of dichlorobenzene (DCB). Toxicity to human being is either by inhalation or ingestion. From Figure $5 \mathrm{c}$ it can be seen that 
proposed stator and rotor material produced $9 \%$ and $7 \%$ lesser DCB emission when compared with the existing one.
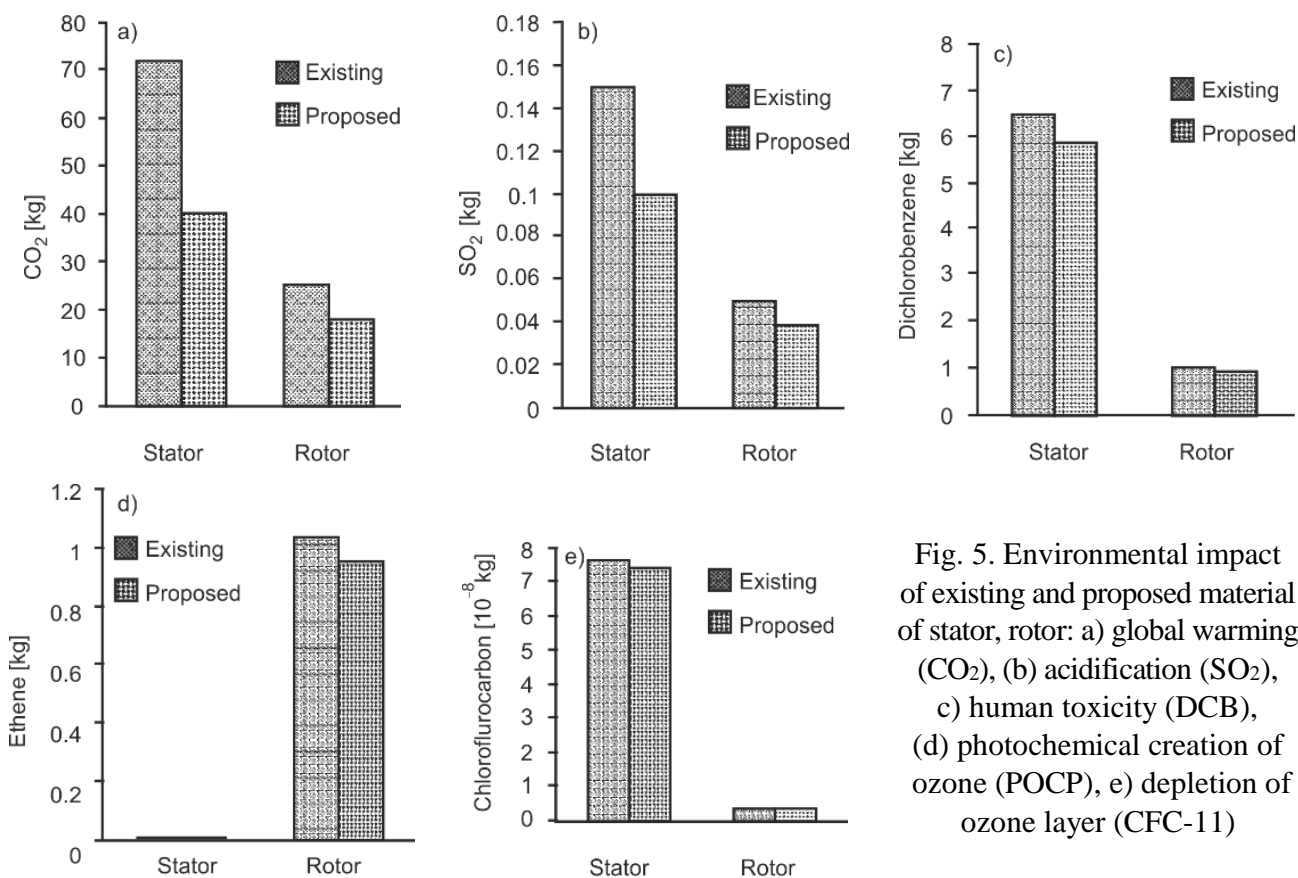

Fig. 5. Environmental impact of existing and proposed material of stator, rotor: a) global warming $\left(\mathrm{CO}_{2}\right),(\mathrm{b})$ acidification $\left(\mathrm{SO}_{2}\right)$,

c) human toxicity (DCB),

(d) photochemical creation of ozone (POCP), e) depletion of ozone layer (CFC-11)

Photochemical ozone creation potential (POCP) is one of the simpler indices of the potential contribution of an organic compound to the formation of groundlevel ozone. The hydrocarbons have been compared in terms of POCP. The environmental investigation shows $33 \%$ and $22 \%$ of reduction in ethane emission as shown in Fig. $5 \mathrm{~d}$ in the proposed material of stator and rotor.

Ozone layer depletion is based on the radiation of chlorofluorocarbons (CFC-11) which causes skin cancer and weakens immune system of human beings. Large fraction of the sun UV-R radiations reaches the surface of the earth due to the diminution of the ozone layer. It indicates that chlorofluorocarbons (CFCs) can deplete the ozone layer. The calculated ozone depletion of the existing and proposed material for both stator and rotor shows only minimum variations shown in Fig. 5e.

\section{CONCLUSION}

The prevention of environmental problems for ensuring clean and green atmosphere is the focus of competitive business organizations. As the inherent concept for the survival in the business domain is sustainability, it is necessary to produce better outcomes 
in manufacturing organizations which can be enabled with LCA. In accordance with life cycle design approach, the production of stator and rotor of a monoblock pump was studied using the LCA method with the cradle-to-grave perspective and the systematic procedure was derived by the CML method. An attempt was made to minimize the environmental impact from the perspectives of material. Selection of materials, elementary scrutinization and detailed process modeling with the implementation of LCA would pave way for good results. The investigation proved that the alternate material for stator (CRGO steel) and rotor (CRGO steel and aluminium alloy) reduces the emission of $\mathrm{CO}_{2}$ by $44 \%$ and $28 \%, \mathrm{SO}_{2}$ by $31 \%$ and $17 \%, \mathrm{DCB}$ emission by $9 \%$ and $7 \%$, ethane emission by $33 \%$ and $22 \%$, respectively, when compared with the existing material of stator (steel) and rotor (steel and aluminium) without changing the efficiency of the pump.

\section{ACKNOWLEDGEMENTS}

The authors are grateful to the Megala Pumps, Coimbatore, India for providing the required facilities and Hindusthan College of Engineering and Technology for providing the required support for completing the research work.

\section{REFERENCES}

[1] World Commission on Environment and Development, Brundtland report on our common future, United Nations, 1987.

[2] VINODH S., JAYAKRISHNA K., Environmental impact minimization in an automotive component using alternative materials and manufacturing process, Mater. Des., 2011, 32, 5082.

[3] YAGI K., Materials design for minimizing environmental load - ecomaterials, Bull Jpn. Inst. Met., 1997, 36 (9), 969.

[4] YANG Q.Z., Life cycle assessment in sustainable product design, SIM Tech Technical Reports 2007, 8, 57.

[5] Song Y.S., Youn J.R., GuTOWSKI T.G., Life cycle energy analysis of fiber reinforced composites, Composites Part A, 2009, 40, 1257.

[6] Ahmad T., May Y.A.S., QATTAwi A., Mayyas A.R., OMAR M.A., Life cycle assessment-based selection for a sustainable lightweight body-in-white design, Energy, 2011, 39, 412.

[7] VINODH S., RATHOD G., Integration of ECQFD and LCA for sustainable product design, J. Clean. Prod., 2010, 18, 833.

[8] KanchanapiYa P., UtAKA J., Life cycle assessment of lead acid battery. Case study for Thailand, Environ. Prot. Eng., 2013, 39, 101.

[9] Senthilkumaran D., Ong S.K., Tan B.H., Nee A.Y.C., Environmental life cycle cost analysis of products, Environ. Manage. Health, 2001, 12 (3), 260.

[10] Kharel G.P., Charmondusit K., Eco-efficiency of iron rod industry in Nepal, J. Clean. Prod., 2008, $16,1379$.

[11] Eliceche A.M., CoRvalan S.M., MARTINEZ P., Environmental life cycle impact as a tool for process optimization of a utility plant, Comput. Chem. Eng., 2007, 31, 648.

[12] VINODH S., JAYAKRISHNA K., JOY D., Environmental impact assessment of an automotive component using eco-indicator and CML methodologies, Clean. Techn. Environ. Policy, 2012, 14, 333.

[13] International Organization for Standards (ISO), Environmental management. Life cycle assessmentPrinciples and framework, ISO 14040, Geneve 2006. 
[14] International Organization for Standards (ISO), Environmental management. Life cycle assessment. Requirements and guidelines, ISO 14044, Geneve 2006.

[15] Pre Consultants, GaBi LCA software, Germany 2010.

[16] Andersson K., Ohlsson T., Olsson P., Screening life cycle assessment (LCA) of tomato ketchup. A case study, J. Clean. Prod, 1998, 6, 277.

[17] Paris H., Museau M., Contribution to the environmental performance of the dry-vibratory drilling technology, CIRP Annals, Manufact. Technol., 2012, 61, 47.

[18] Monteiro H., Freire F., Life cycle assessment of a house with alternative exterior walls. Comparison of three impact assessment methods, Energy Build., 2012, 47, 572.

[19] GonZalez-Garcia S., Hospido A., Moreira M., Romero J., FeiJoo G., Environmental impact assessment of total chlorine free pulp from Eucalyptus globulus in Spain, J. Clean. Prod., 2009, 30, 1. 